\title{
Percutaneous aortic interventions in patients with severe valvular aortic stenosis
}

\author{
Intervenciones percutáneas aórticas en pacientes con estenosis valvular \\ aórtica severa
}

Igor F. Palacios ${ }^{1}$

\begin{abstract}
The treatment of choice for symptomatic severe aortic stenosis is aortic valve replacement (AVR).

Percutaneous aortic valvuloplasty (PVA) is associated with improvement in symptoms and hemodynamic parameters but major complications and the high rate of restenosis at year are the main limitations.

We present 310 patients with symptomatic severe aortic stenosis not surgical candidates who received 394 consecutive PVA between 1986 and 1993 at the Massachusetts General Hospital. A group of these patients underwent follow-up of aortic valve replacement (AVR). When these two groups was compared patients who received PVA as a bridge to AVR versus patients who received only PVA showed higher survival at follow-up.

The subgroup of patients with severe aortic stenosis and cardiogenic shock have significantly improved clinical and hemodynamic parameters after the PVA.

Since Alan Cribier in 2002 implanted the first percutaneous aortic valve (TAVI) in a patient inoperable this method has expanded exponentially. Currently being used two types of devices, the expandable balloon valve (Edwards Lifesciens, Irvine, California) and the self-expanding valve (Valve core, Irvine, California). The PARTNER Trial Cohort B was the first randomized trial comparing patients with symptomatic severe aortic stenosis inoperable with TAVI versus standard therapy, where it was observed that the TAVI mortality was significantly lower than with standard therapy. This difference persisted after two years. Based on this trial in 2011 the FDA approved the use of this device for inoperable patients. The PARTNER Trial Cohort A randomly compared in patients with symptomatic severe aortic stenosis at high surgical risk TAVI versus AVR, where it was observed that TAVI was not-inferior than AVR at year. However, the rate of stroke was higher the percutaneous group.

Within the limitations of the TAVI are the stroke, perivalvular aortic insufficiency, complications in the access and the need for new pacemaker.

The dream of percutaneous aortic valve implantation is a reality. Patient selection, using different images for evaluating the valve and the role of vital multidisciplinary team to perform effective implant. The continuous development and improvement of these devices will be the key to success is increased, reduce complications and extend the indications to different groups.
\end{abstract}

Key words: aortic stenosis, aortic valve implantation, high-risk.

1. Cardiac Unit, Massachusetts General Hospital and Harvard Medical School, Boston, Massachusetts, USA.

$\square$ Address for reprints: Igor F. Palacios, MD. Director of Interventional Cardiology and Director of Percutaneous Interventions for Structural Heart Diseases, Massachusetts General Hospital, Harvard Medical School. Boston, MA 02114, Tel: 617-726-8424, Fax: 617-726-6800 | ipalacios@ partners.org

Recibido: 9-7-2012 | Aceptado: 17-8-2012

\section{INTRODUCTION}

The only definitive treatment for patients with symptomatic severe aortic stenosis is surgical aortic valve replacement. The development of symptoms due to aortic stenosis provides a clear indication for aortic valve replacement. For patients who are not candidates for aortic replacement, percutaneous aortic balloon valvuloplasty may provide some symptomatic relief. Medical treatment (such as diuretic therapy) in aortic stenosis may provide temporary symptom relief but is generally not effective long term. 


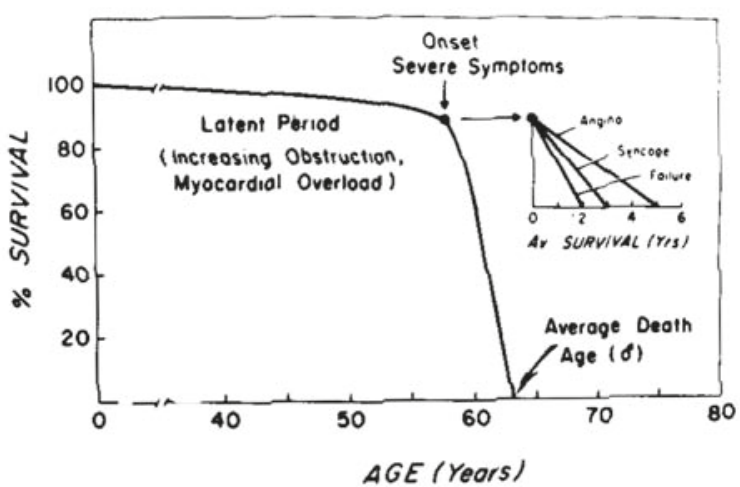

Figure 1. Natural history of patients with aortic stenosis. After a long latent period symptoms eventually occur in patients with aortic stenosis. When symptoms of angina, syncope, or heart failure develop, the outlook of these patients changes dramatically.

Over the last 2-3 decades, percutaneous aortic balloon valvuloplasty (PAV) and during the last decade percutaneous aortic valve replacement (TAVI) have emerged as effective treatment modalities for the treatment of patients with severe aortic stenosis. The immediate and long term beneficial effects of balloon valvuloplasty has been demonstrated in patients with pulmonic stenosis, mitral stenosis, non calcified aortic stenosis and tricuspid stenosis. Balloon valvuloplasty provides better results in those stenotic lesions in which commissure fusion is an important component of the underlying mechanism for stenosis such as is the case in patients with congenital pulmonic stenosis, non calcified aortic and rheumatic mitral stenosis.

Although balloon valvuloplasty results in sub-optimal immediate outcome and higher restenosis rates in elderly patients with degenerative calcific aortic stenosis, percutaneous balloon valvuloplasty could be used in them as a life saving procedure and as bridge to surgical AVR or TAVI. The hemodynamic improvement produced by PAV allows for improvement of associated comorbids conditions and offers a window of opportunity for a successful bridge to surgical or percutaneous aortic valve replacement.

\section{AORTIC BALLOON VALVULOPLASTY}

Severe degenerative calcified aortic stenosis is the most frequent valvular heart disease in Western hemisphere countries. The natural history of calcific aortic stenosis is well known. After a long latent period symptoms eventually occur in patients with aortic stenosis. When symptoms of angina, syncope, or heart failure develop, the outlook of these patients changes dramatically (Figure 1). After the onset of symptoms, average survival is less than 2 to 3 years. Thus, the development of symptoms identifies a critical point in the natural history of aortic stenosis. Management decisions are based largely on this natural history data; many

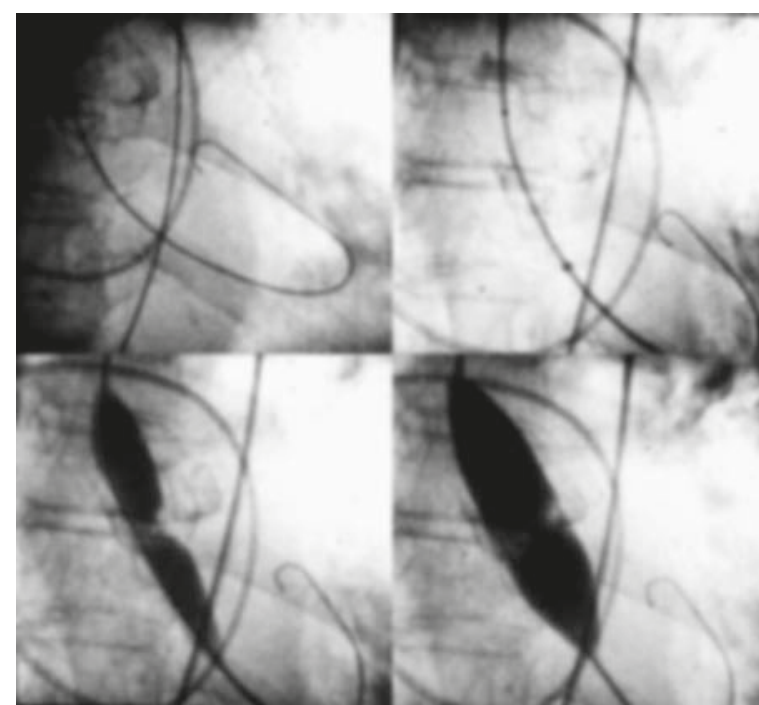

Figure 2. Retrograde aortic balloon valvulopalsty, Following retrograde crossing of the aortic valve a $0.038^{\prime \prime}$ Amplatz exchange wire with a curled tip is placed into the left ventricle and the retrograde catheter removed. A balloon dilating catheter chosen according the aortic annulus is advanced and inflated across the stenotic aortic valve until the indentation produced by the stenotic valve is resolved.

clinicians treat asymptomatic patients conservatively, whereas corrective surgery is generally recommended in patients with symptoms thought to be due to aortic stenosis. Surgical aortic valve replacement (AVR) is the treatment of choice for patients with symptomatic, severe aortic stenosis. ${ }^{1-4}$ However, associated major medical comorbid conditions increase perioperative complications significantly, and in some cases the risk is so high that surgeons classify these patients as non-surgical or very high-risk surgical candidates. Furthermore, previous bypass surgery, severe congestive heart failure, low left ventricular ejection fraction, recent myocardial infarction, diabetes mellitus, renal failure and most of all, emergent operation, are independent predictors for operative death in elderly patients undergoing AVR ${ }^{5-8}$ Finally, $54 \%$ of octogenarians require concomitant surgical procedures including coronary artery bypass surgery and/or mitral valve replacement., Elective perioperative mortality for octogenarians undergoing AVR-CABG is 24\%.' Emergent perioperative mortality increase to $37 \%$ in patients with severe congestive heart failure requiring pressors ${ }^{10}$ and can be as high as $50 \%$ in patients with cardiogenic shock. ${ }^{11}$ Furthermore, complicated postoperative course including encephalopathy with discharge to a rehabilitation facility is present in $38 \%$ of the patients. ${ }^{12}$

Since the initial report by Cribier et al. in 1986, ${ }^{13}$ percutaneous aortic balloon valvuloplasty (PAV) has been considered as a palliative form of treatment for elderly patients with calcific aortic stenosis. PAV is associated with significant immediate clinical and hemodynamic improvement. ${ }^{14,15}$ However, the risk of major complications and the high restenosis rate during the first year are major limitations of this technique. ${ }^{16,17}$ In fact, since PAV does not change the natural history 


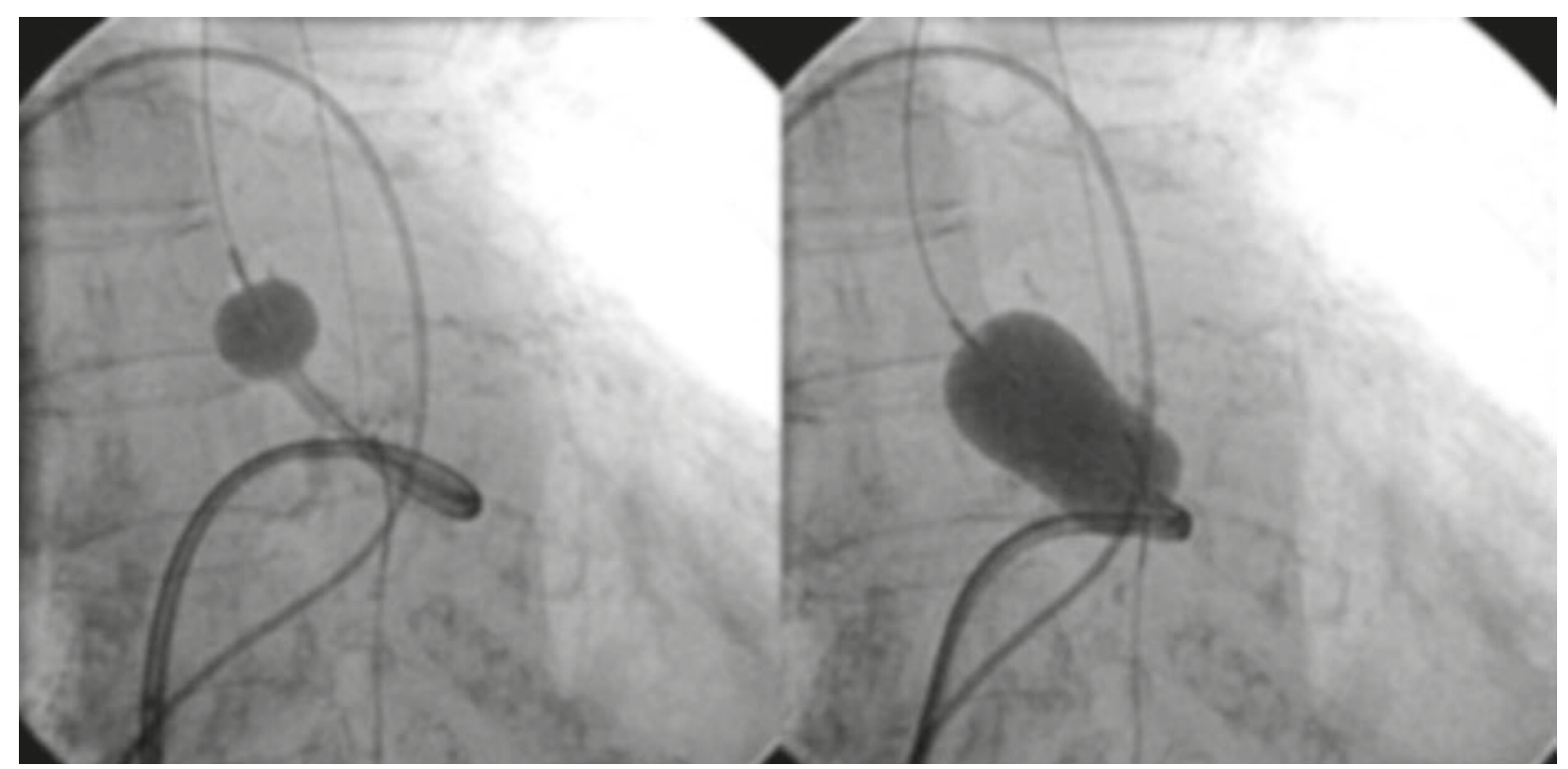

Figure 3. Transseptal, antegrade aortic balloon valvulopalsty using the Inoue balloon catheter, Following transseptal left heart catheterization a balloon tip catheter is advanced from the right atrium into the left atrium and then across the mitral valve into the ascending and descending aorta across the stenotic aortic valve. A $0.025^{\prime \prime}$ Amplatz exchange wire is advanced through the balloon catheter into the ascending aorta. The tip of the guide wire is snare from the decsnding aorta with the use of a 5 French Microvena snare catheter and the balloon catheter removed. Thereafter a $26 \mathrm{~mm}$ Inoue balloon catheter is advanced antegrade across the aortic valve and inflated at a volume between 20 to 24 cc according to the aortic until the indentation produced by the stenotic valve is resolved.

of severe aortic stenosis ${ }^{18-21}$ its use in some institutions was abandoned..$^{22}$ Therefore, elderly patients with profound hemodynamic instability due to severe aortic stenosis present a challenging dilemma in critical care medicine. Nevertheless, if surgery is not an option, PAV can be effectively use as a life saving procedure for immediate relief of the transaortic valve gradient with subsequent hemodynamic stabilization and further consideration for elective bridge to AVR or TAVI.

\section{Procedure}

Percutaneous balloon aortic valvuloplasty can be performed using either the retrograde or the antegrade techniques. ${ }^{15}$ The results of PAV can be assessed during the procedure by use of measurements of valve area by hemodynamics. However, the value of these measurements is highly questionable because the hemodynamic instability of the patients during the procedure and the very early loss in valve area after the PAV procedure. Perhaps a better method to assess the results is the measurement of aortic gradient and aortic valve area by echo Doppler technique the day after the procedure.

\section{Retrograde technique}

After crossing the aortic valve and determining resting hemodynamics, a 0.038 " Amplatz type heavy exchange wire is advanced through the retrograde catheter and placed into the left ventricular cavity. The retrograde catheter is then removed leaving the guide wire across the stenotic aortic valve coiled in the left ventricular apex. A dilating balloon catheter chosen according with the size of the aortic annulus is then advanced over the guide wire, placed across the aortic valve and inflated by hand (Figure 2).

\section{Antegrade technique}

The left atrium is entered using transseptal catheterization with a modified Bronckenbrough needle and a Mullin's sheath. A balloon wedge catheter is advanced through the Mullin's sheath and passed into the left ventricle and then antegrade through the stenotic aortic valve. A soft 0.038 " exchange wire is advanced through the catheter into the ascending and descending aorta and the catheter and Mullin's sheath are removed. A 5 $\mathrm{mm}$ balloon dilating catheter is used to dilate the atrial septum and the aortic valve. After removal of this catheter, a chosen dilating balloon catheter is then advanced antegrade across the mitral valve, placed across the aortic valve and inflated. A variety of the transseptal antegrade technique using the Inoue balloon has also been reported. With technique a 26-mm Inoue balloon catheter (at maximum balloon volume of $22-25 \mathrm{cc}$ ) is advanced antegrade over a 0.025 " exchange length Amplatz type guide wire that has been advanced transseptally from the right atrium into the left atrium and left ventricle and then antegrade across the aortic valve into the ascending and descending aorta. Advancing of the balloon catheter is facilitated by snare of the guide wire into the descending aorta from either of the femoral arteries (Figure 3).

With both retrograde and antegrade techniques, multiple balloon inflations are performed to relieve the stenosis. To monitor systemic blood pressure during and immediately after balloon inflations, an arterial line should be in place before the inflations. In two third of the patients inflations are well tolerated and longer balloon inflations (> $30 \mathrm{sec}$ ) can be performed. In the other third of the patients only short balloon inflations (15 to $30 \mathrm{sec}$ ) can be performed because 


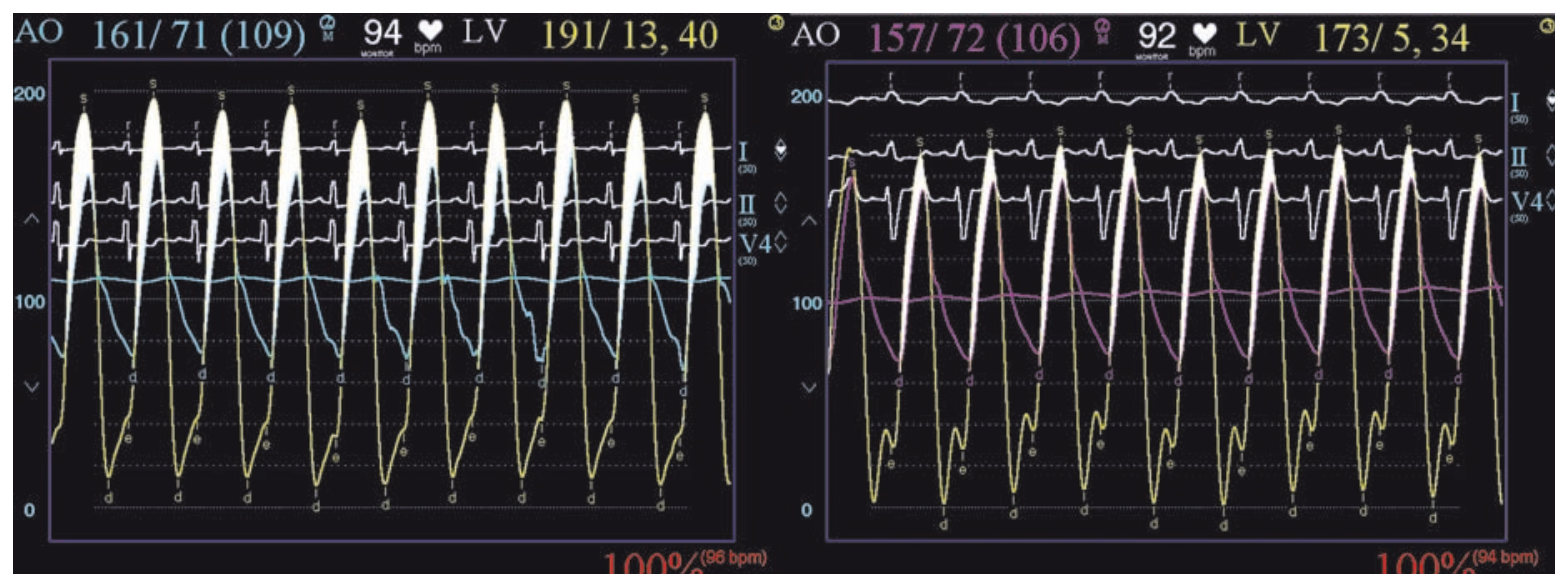

Figure 4. Simultaneous left ventricular and arterial pressure in one patient before and immediately after PAV. A significant decrease in aortic gradient and an increase in aortic valve area are seen.
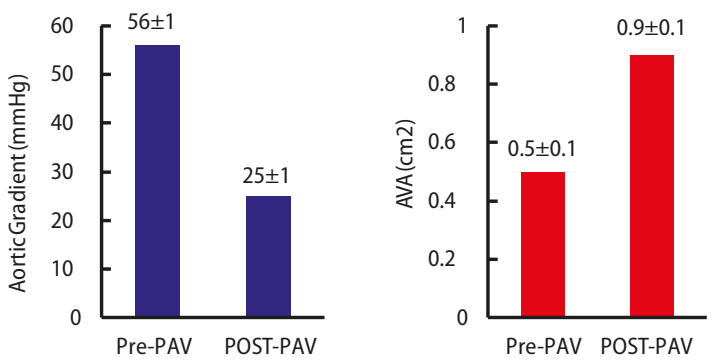

Figure 5. Mean changes in mean systolic aortic gradient and an in mean aortic valve area following PAV in the overall patient population.

of significant hypotension during balloon inflation. Short balloon inflations and longer period between inflations are used in patients with severe depression of left ventricular ejection fraction as well as in patients with severe coronary artery disease. The size of the dilating balloon catheter (18 to $25 \mathrm{~mm}$ in diameter, Boston Scientific, Waltham, MA, or $18-25 \mathrm{~mm}$ in diameter MAXY balloon valvuloplasty Cordis Corporation, a Johnson \& Johnson company, Bridgewater, NJ 08807), or 26-mm Inoue balloon catheter, Toray Inc) is chosen according with the size of the aortic annulus (not greater than $100 \%$ of annulus) determined by 2D-echocardiography or angiography.

Hemodynamic measurement and cardiac output using the thermodilution method are determined before and after completion of the procedure (Figure 4). For patients with significant tricuspid regurgitation and/or left to right shunting cardiac output is determined using the Fick method. The aortic valve area $(\mathrm{cm} 2)$ is calculated using the Gorlin equation. ${ }^{23}$ Aortic valve resistance (dynes. sec.cm5) proposed as a better indicator of the hemodynamic significance of aortic stenosis before and after PAV, can be calculated as previously described. ${ }^{24}$ Left ventricular ejection fraction is calculated by contrast ventriculography or $2 \mathrm{D}$-echocardiography.

\section{Patient population}

The patient population includes 310 symptomatic patients with severe, calcific, aortic stenosis who under-
Table 1. Associated comorbid conditions of patients undergoing PAV

\begin{tabular}{|l|c|}
\hline Conditions & \# Patients \\
\hline COPD & $64(21 \%)$ \\
\hline CRF & $64(21 \%)$ \\
\hline PVD & $54(17 \%)$ \\
\hline CANCER & $48(15 \%)$ \\
\hline CVA & $48(15 \%)$ \\
\hline Other & $112(38 \%)$ \\
\hline
\end{tabular}

Liver failure, Hip Fracture, Gl bleeding, Complicated Diabetes, Alzheimer, Sepsis, Thyroid disease, AIDS.

Table 2. Hemodynamic parameters pre and post PAV

\begin{tabular}{|l|c|c|c|}
\hline Variables & pre-PAV & post-PAV & p \\
\hline Mean Ao gradient $(\mathrm{mm} \mathrm{Hg})$ & $56 \pm 1$ & $25 \pm 1$ & 0.0001 \\
\hline Cardiac Output $(\mathrm{L} / \mathrm{min})$ & $3.7 \pm 0.1$ & $3.9 \pm 0.1$ & 0.0001 \\
\hline Aortic Valve Area $(\mathrm{cm} 2)$ & $0.49 \pm 0.01$ & $0.87 \pm 0.02$ & 0.0001 \\
\hline Systolic aortic pressure $(\mathrm{mm} \mathrm{Hg})$ & $129 \pm 2$ & $144 \pm 2$ & 0.0001 \\
\hline Systolic PA pressure $(\mathrm{mm} \mathrm{Hg})$ & $49 \pm 1$ & $45 \pm 2$ & 0.03 \\
\hline
\end{tabular}

Values are expressed in mean \pm SEM.

went 394 PAV at the Massachusetts General Hospital between February of 1986 and February of $1993 .{ }^{19}$ They were considered non-or very high risk surgical candidates at the time of presentation because of associated major comorbid conditions. In addition, PAV was performed in patients with severe aortic stenosis discovered at the time of evaluation for major non cardiac surgery, in 65 patients who presented with symptomatic aortic valve restenosis after a previous successful procedure (Redo-PAV), and in 21 patients who presented in cardiogenic shock due to critical aortic stenosis. There were 180 females and 130 males with a mean \pm SEM age of $79 \pm 1$ (range: $35-96)$ years. Mean left ventricular ejection fraction was $48 \pm 15$ (range: 10$81) \%$. Ninety percent of the patients were in NYHA functional class III-IV. All patients had more than one major comorbid condition (average 1.3/patient) at the time of presentation, including chronic renal failure, previous stroke, severe chronic obstructive pulmonary disease, liver failure, hip fracture, pulmonary hemorrhage, pulmonary embolism, Alzheimer disease, sepsis, diabetes with multiple organ complications, thy- 


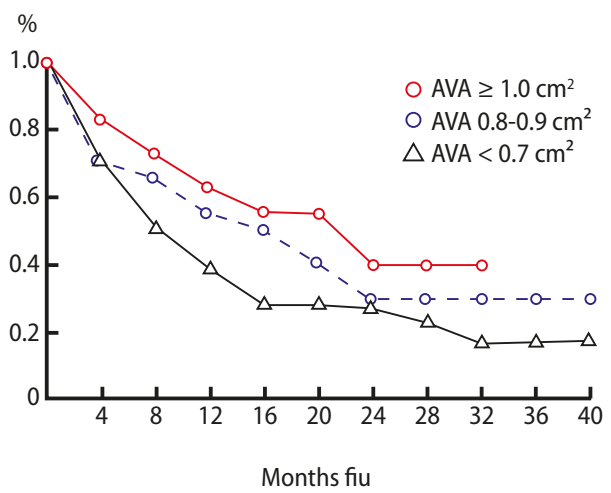

Figure 6. Sixty month actuarial survival of patients undergoing percutaneous aortic balloon valvuloplasty at the Massachusetts General Hospital.

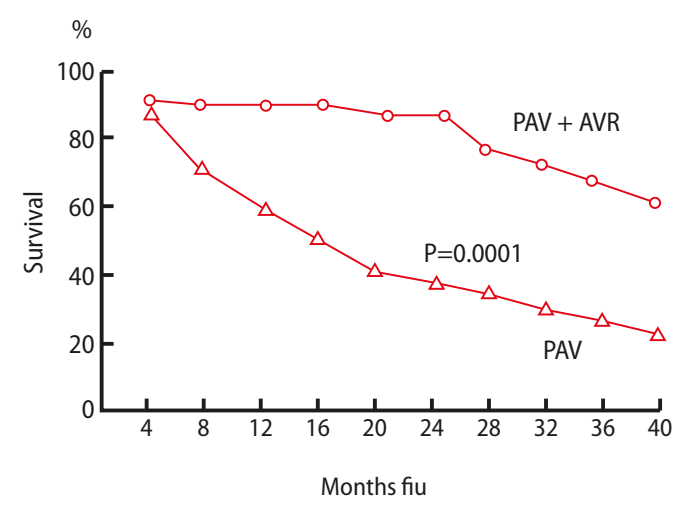

Figure 8. Comparative actuarial survival for patients undergoing percutaneous aortic balloon valvuloplasty as a bridge to aortic valve replacement with those who did not undergo AVR.

roid disease, bleeding disorders, incapacitating arthritis, multiple myeloma and AIDS. Major comorbid conditions are shown in Table $\mathbf{1 .}$

\section{Results}

The hemodynamic changes produced by PAV are shown in Table 2 and Figures $\mathbf{4}$ and 5. PAV resulted in significant decrease in mean systolic aortic gradient from $56 \pm 1$ to $25 \pm 1 \mathrm{~mm} \mathrm{Hg}$ ( $\mathrm{p}=0.0001$ ) and a significant increase in both cardiac output from $3.7 \pm 0.06$ to $3.9 \pm 0.06 \mathrm{~L} / \mathrm{min}(\mathrm{p}=0.0001)$ and aortic valve area from $0.5 \pm 0.01$ to $0.9 \pm 0.02 \mathrm{~cm}^{2}$ ( $\left.\mathrm{p}=0.0001\right)$. Thus, PAV decreases the severity of aortic stenosis from severe to moderate stenosis with post PAV valve areas between 0.7 and $1.1 \mathrm{~cm}^{2}$. This result is clearly inferior to the valve area obtained with surgical aortic valve replacement, which usually provides a valve area $>1.5$ $\mathrm{cm}^{2}$. As expected from the pathophysiology of severe degenerative aortic stenosis, ie, absence of commissural fusion and extensive calcification, PAV has only limited efficacy. The mechanism of PAV underlying relief of the stenotic lesion in older adults is fracture of calcific deposits within the valve leaflets and to some degree

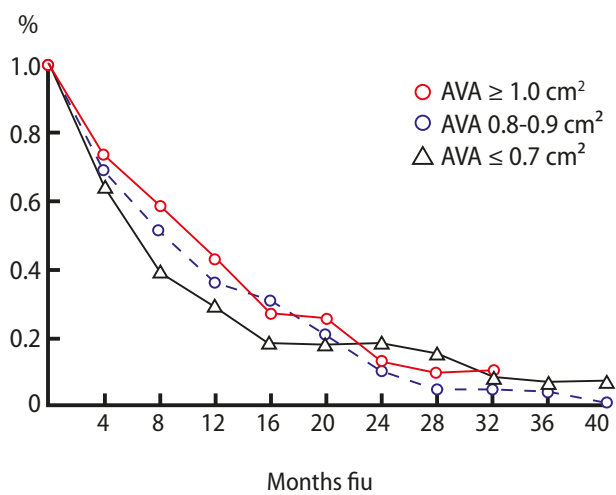

Figure 7. Sixty month actuarial event free survival of patients undergoing percutaneous aortic balloon valvuloplasty at the Massachusetts General Hospital.

Table 3. PAV as a Bridge to AVR.

\begin{tabular}{|l|c|c|c|}
\hline & AVR & Control & p \\
\hline Patients & 40 & 270 & \\
\hline Age (years) & $75 \pm 2$ & $80 \pm 1$ & 0.003 \\
\hline Ejection Fraction (pre PAV) & $0.47 \pm 0.15$ & $0.49 \pm 16$ & NS \\
\hline Mean Aortic gradient (mmHg) \\
\hline pre PAV & $57 \pm 3$ & $56 \pm 1$ & NS \\
\hline post PAV & $26 \pm 2$ & $25 \pm 1$ & NS \\
\hline Cardiac Output (I/min) & $4.2 \pm 0.2$ & $3.6 \pm 0.2$ & 0.003 \\
\hline pre PAV & $4.5 \pm 0.2$ & $3.8 \pm 0.2$ & 0.001 \\
\hline post PAV & $0.6 \pm 0.04$ & $0.5 \pm 0.01$ & 0.006 \\
\hline Aortic Valve Area $\left(\mathrm{cm}^{2}\right)$ & $1.0 \pm 0.07$ & $0.9 \pm 0.02$ & 0.03 \\
\hline pre PAV
\end{tabular}

stretching of the annulus and separation of the calcified or fused commissures.

\section{Complications}

Procedural mortality (death in the catheterization laboratory) occurred in 12 pts (3\%), in-hospital (30 day) mortality occurred in 34 pts (8.6\%); local vascular complications in 49 patients (12\%) including need for vascular surgery in 38 patients $(9.6 \%), 2$ of who required leg amputation (0.5\%). Cerebrovascular accident occurred in 5 patients $(1.2 \%)$, severe aortic regurgitation in 6 patients (1.5\%), acute renal failure in $7 \mathrm{pa}$ tients (1.7\%), significant atrial septal defect in $2 \mathrm{pa}-$ tients $(0.5 \%)$ who had antegrade PAV, cholesterol emboli in 3 patients $(0.8 \%)$, non-fatal ventricular fibrillation in 7 patients (1.7\%), myocardial infarction in 6 patients (1.5\%), and left ventricular perforation in 1 patient $(0.2 \%)$.

\section{Long term follow-up}

Estimated actuarial survival at 1,3 , and 5 years were: $55 \pm 3 \%, 25 \pm 3 \%$, and $22 \pm 3 \%$ (Figure 6). The corresponding estimated actuarial event free survival were: $33 \pm 2 \%, 13 \pm 2 \%$, and $2 \pm 1 \%$ respectively (Figure 7 ).

\section{PAV as a bridge to aortic valve replacement}

From our cohort of 310 patients who underwent PAV 
at the Massachusetts General Hospital there were 40 patients (14\%), 21 males and 19 females, mean age of $75 \pm 2$ years who underwent aortic valve replacement (AVR) $6 \pm 1$ months after PAV. When compared with the group that did not undergo AVR after PAV ( $n=270)$, the group of patients bridged to AVR were younger $(p=0.003)$, had a higher cardiac output $(\mathrm{p}<0.003)$, higher aortic valve area $(\mathrm{p}=0.006)$ and higher left ventricular end diastolic pressure $(p<0.034)$ before PAV (Table 3). Left ventricular ejection fraction was similar in both groups. With PAV, the mean aortic gradient decreased from $57 \pm 3$ to $26 \pm 2 \mathrm{~mm}$ $\mathrm{Hg}(\mathrm{p}<0.001)$, the cardiac output increased from $4.2 \pm 1$ to $4.5 \pm 1$ Liters $/ \mathrm{min}(\mathrm{p}=0.11)$ and the aortic valve area increased from $0.6 \pm 0.04$ to $1.0 \pm 0.07$ $\mathrm{cm}^{2}(\mathrm{p}<0.001)$. Patients that underwent AVR had both, higher cardiac output $(p<0.001)$, and larger aortic valve area $(p=0.03)$ after PAV than the group of patients that did not undergo AVR. In hospital surgical mortality was $10 \%$. There were 7 deaths occurring at $18 \pm 6$ months after PAV. There was a significant improvement in symptoms after AVR. At a mean follow up of $35 \pm 3$ months, $87 \%$ of the patients bridged to AVR after PAV were in NYHA class I-II and $13 \%$ were in class III-IV. As shown in Figure 8 estimated actuarial survival curves at one, three and five years were significantly better for the group of patients bridged to AVR after PAV.

\section{Cardiogenic shock}

Percutaneous aortic balloon valvuloplasty can be performed successfully in patients with cardiogenic shock due to severe aortic stenosis. In these patients, PAV resulted in a significant decrease in aortic gradient and a significant increase in aortic valve area and systolic arterial pressure in $90 \%$ of these moribund patients. From our cohort of 310 patients who underwent PAV at the Massachusetts General Hospital there were 21 patients, 10 males and 11 females, mean age of $74 \pm 3$ (range 35-90) years, mean left ventricular ejection fraction of $29 \pm 3 \%$ (range 15-61\%) underwent PAV for cardiogenic shock. All patients met the following criteria of cardiogenic shock:

1. Sustained arterial hypotension with systolic blood pressure $<90 \mathrm{~mm} \mathrm{Hg}$ despite maximal inotropic and pressor pharmacological support;

2. Cardiac index $<2.21 / \mathrm{min} / \mathrm{m} 2$;

3. Mean pulmonary capillary wedge pressure and/or LVEDP > $20 \mathrm{~mm} \mathrm{Hg}$;

4. Urinary output $<0.5 \mathrm{ml} / \mathrm{kg} / \mathrm{hr}$;

5. Clinical evidence of decreased tissue perfusion.

The hemodynamic characteristics of patients with and without cardiogenic shock are shown in table 4. Before PAV, patients with cardiogenic shock exhibit a lower left ventricular ejection fraction $(\mathrm{p}=0.001)$, and lower
TABLE 4. PAV for Cardiogenic Shock due to Aortic Stenosis.

\begin{tabular}{|l|c|c|c|}
\hline & $\begin{array}{c}\text { Cardiogenic } \\
\text { shock }\end{array}$ & Control & p \\
\hline Patients & 21 & 289 & \\
\hline Age (years) & $74 \pm 3$ & $79 \pm 2$ & 0.001 \\
\hline NYHA & $4 \pm 0$ & $3.4 \pm 0.04$ & 0.0001 \\
\hline LVEF (pre PAV) & $29 \pm 3$ & $49 \pm 1$ & 0.0001 \\
\hline Mean Aortic gradient (mmHg) \\
\hline pre PAV & $49 \pm 4$ & $57 \pm 1$ & 0.05 \\
\hline post PAV & $21 \pm 3$ & $25 \pm 1$ & NS \\
\hline Cardiac Index $\left(/ / \mathrm{min}^{\prime} / \mathrm{m}^{2}\right)$ & $1.8 \pm 0.1$ & $2.2 \pm 0.03$ & 0.003 \\
\hline pre PAV & $2.2 \pm 0.1$ & $2.4 \pm 0.04$ & NS \\
\hline post PAV & $0.5 \pm 0.04$ & $0.5 \pm 0.01$ & NS \\
\hline Aortic Valve Area $\left(\mathrm{cm}^{2}\right)$ & $0.8 \pm 0.06$ & $0.9 \pm 0.02$ & NS \\
\hline pre PAV &
\end{tabular}

NYHA: New York Heart Association. LVEF: left venticular ejection fraction.

cardiac index $(\mathrm{p}<0.0003)$, than the group of patients without cardiogenic shock. After PAV, patients in cardiogenic shock had a significant reduction in mean aortic gradient from $49 \pm 4$ to $21 \pm 3 \mathrm{~mm} \mathrm{Hg} \mathrm{(p=}$ 0.0001 ), a borderline improvement in cardiac index from $1.8 \pm 0.1$ to $2.2 \pm 0.1 \mathrm{l} / \mathrm{min} / \mathrm{m} 2(\mathrm{p}=0.06)$ and a significant improvement in aortic valve area from 0.5 \pm 0.04 to $0.8 \pm 0.06 \mathrm{~cm} 2(p=0.0001)$ (Table 4). Sixteen patients were successfully weaned from the inotropic support in the first 24 hours after the procedure. Complications included: Procedural mortality in $2 \mathrm{pa}-$ tients (9.5\%), total in-hospital (30 day) mortality in 9 patients (43\%), local vascular complications in 5 patients $(24 \%)$, local vascular surgery in 3 patients $(14 \%)$, cerebrovascular accident in 1 patient (5\%), severe aortic regurgitation in 1 patient (5\%), and cholesterol embolization in 1 patient (5\%). The major cause of in-hospital mortality was multi-organ failure despite successful PAV.

Actuarial survival was $38 \pm 11 \%$ at 27 months followup. Cox regression analysis identified post PAV cardiac index as the only predictor for longer survival $(p=0.02)$. Although high, the procedure-related mortality after PAV in this group of patients with cardiogenic shock compares favorably with the extremely high mortality rate reported in previous surgical studies in patients with cardiogenic shock and severe aortic stenosis. ${ }^{10,11}$ However, surgical correction with aortic valve replacement is the only therapy that will alter the natural history of severe, symptomatic aortic stenosis in the elderly. There are important guidelines that have to be kept in mind managing elderly patients with cardiogenic shock due to critical aortic stenosis: 1) Sustained hypotension associated with severe congestive heart failure constitute a medical emergency. Pharmacologic therapy and bedside hemodynamic monitoring should be started immediately. 2) There is no time for procrastination and emergent interventional therapy (PAV or AVR) should be done as soon as possible. 3) PAV should be considered as a bridge to AVR or TAVI. Therefore, AVR with myocardial revas- 


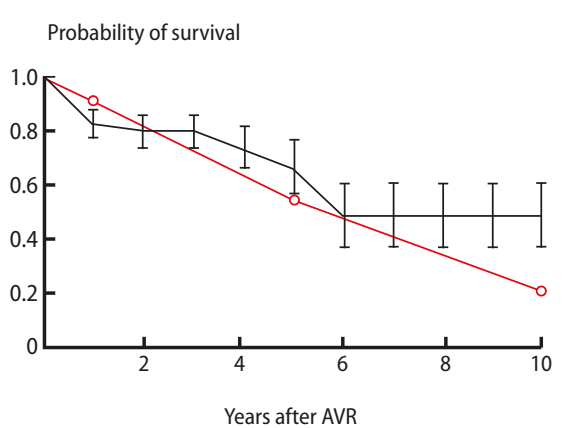

Figure 9. Comparative actuarial survival for octogenarian patients with severe aortic stenosis. Surgical AVR alone or in combination with CABG or other valvular surgery is superior to PAV. Note that PAV does not change the natural history of aortic stenosis in the elderly with calcific stenosis.

cularization if needed should be performed early after percutaneous aortic balloon valvuloplasty. ${ }^{22}$

\section{Conclusions}

Surgical aortic valve replacement is the procedure of choice for the treatment of patients with symptomatic aortic stenosis. Percutaneous balloon aortic valvotomy has an important role in treating adolescents and young adults with aortic stenosis but a very limited role in older adults. Immediate hemodynamic results include a moderate reduction in the transvalvular pressure gradient, but the post-valvotomy valve area rarely exceeds $1.0 \mathrm{~cm}^{2}$. Despite this modest change in valve area, an early symptomatic improvement is usually seen. However, serious complications occur with a frequency $>10 \%$; restenosis and clinical deterioration occur within 6 to 12 months in most patients. Therefore, in adults with aortic stenosis, balloon valvotomy is not a substitute for AVR. Because there is no effective medical therapy and balloon valvotomy is not an acceptable alternative to surgery, AVR must be considered in all elderly patients who have symptoms caused by aortic stenosis. Valve replacement is technically possible at any age, but the decision to proceed with such surgery depends on many factors, including the patient's wishes and expectations. Older patients with symptoms due to severe aortic stenosis, normal coronary arteries, and preserved LV function can expect a better outcome than those with coronary disease or ventricular dysfunction. Certainly advanced cancer and permanent neurological defects as a result of stroke make cardiac surgery inappropriate. Deconditioned and debilitated patients often do not return to an active existence, and the presence of the other comorbid disorders may have a major impact on outcome.

It is now recognized that PAV does not change the natural history of patients with calcific severe aortic

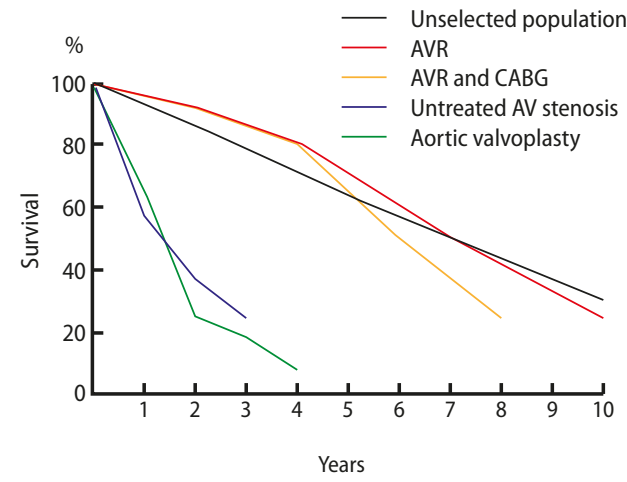

Figure 10. Comparative actuarial survival for patients with severe aortic stenosis treated with surgical AVR alone or in combination with CABG, or PAV and octogenarian without aortic stenosis according with the Massachusetts Census. Note that PAV does not change the natural history of aortic stenosis in the elderly with calcific stenosis.

stenosis (Figure 9 and 10). Most groups have abandoned this technique, whereas for others, it would appear that there is a limited role for it use in critically ill patients with cardiogenic shock and multisystem failure, in patients who must undergo emergency non cardiac major surgery, in patients that refuse surgery and as a palliative procedure in patients with absolute but non-life threatening short term contraindications to surgery when a significant disability and comorbid conditions exist and as bridge to subsequent AVR. All these indications for PAV are Grade B. Finally, PAV may help to identify patients likely to benefit from AVR among those patients with severe depression of LVEF presenting with small gradient, low cardiac output, and therefore calculated small aortic valve area.

\section{FUTURE DIRECTIONS: PERCUTANEOUS AORTIC VALVE IMPLANTATION (TAVI)}

A dramatic change occurred over the next decade as the emergence of transcatheter heart valve repair techniques significantly reduced the risk and cost associated with heart valve procedures. Animal and human studies indicate that non-surgical techniques to valve replacement and repair are feasible. These techniques have already been applied safely to human with artificial pulmonary artery trunk. Percutaneous transcatheter replacement of the pulmonic valve was introduced by Bonhoeffer et al., ${ }^{25}$ and percutaneous valve replacement of calcific aortic stenosis by Cribier et al. Allen Cribier reported the first implantation of a percutaneous balloon-expandable prosthetic heart valve in a human in April of 2003. ${ }^{26}$ A 57-year-old man presented to a French hospital with cardiogenic shock and a severely calcified bicuspid valve. Transthoracic echocardiography showed a mean transvalvular gradient of 30 $\mathrm{mm} \mathrm{Hg}$, an aortic valve area of $0.6 \mathrm{~cm}^{2}$, and a LV ejec- 
Edwards Sapien Valve

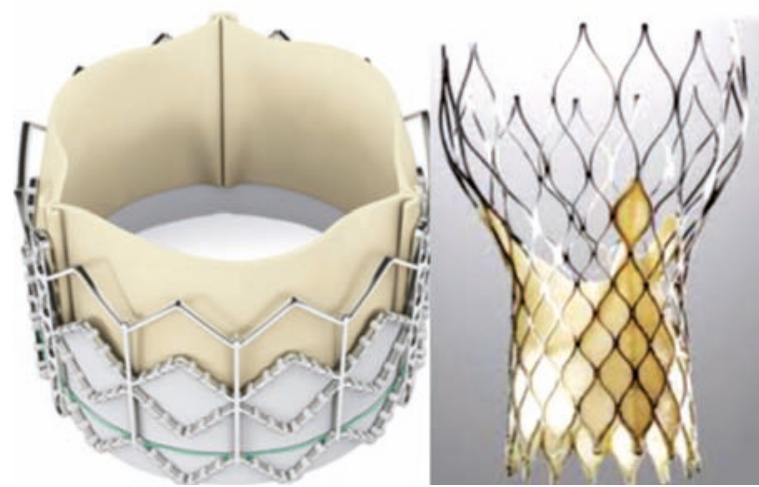

Figure 11. The two available first generation TAVI system. The Edwards Sapien balloon expandable valve and the Core-Valve self expandable valve.

tion fraction of $14 \%$. The man's medical history included peripheral vascular disease, silicosis, lung cancer, and chronic pancreatitis, thereby precluding surgical valve replacement. The patient was treated initially with percutaneous balloon valvuloplasty, but shock persisted, prompting investigational insertion of the stent prosthesis. The prosthesis consisted of 3 bovine pericardial leaflets mounted within a tubular, slotted, stainless-steel, balloon-expandable, 14-mm-long stent, which was delivered on a 30-mm-long x 23-mm-diameter balloon using an antegrade transseptal approach. Hemodynamic measurements immediately after valve insertion included a mean transvalvular gradient of 6 $\mathrm{mm} \mathrm{Hg}$ and a calculated aortic valve area of $1.9 \mathrm{~cm}^{2}$ (1.6 $\mathrm{cm}^{2}$ by transesophageal echo). LVEF improved to $17 \%$. There was mild-to-moderate paravalvular aortic regurgitation through a non-apposed calcified commissure. Neither coronary ostium was compromised. Valve function remained stable for 9 weeks, but the patient developed multiple noncardiac complications and died 17 weeks after valve implantation. This dramatic case demonstrated the feasibility of percutaneous heart-valve implantation for calcific aortic stenosis. Future refinements in design and insertion technique allowed this approach to become a therapeutic alternative to surgery in selected patients. The pioneer work by these two investigators represents a milestone that opened a new era of interventional cardiology.

\section{TAVI procedure}

Patients are premedicated with clopidogrel and aspirin and received Vancomycin or Cefazolin $1 \mathrm{~g}$ IV immediately before the procedure. The procedure is performed in a hybrid room in the catheterization laboratory with operating room-like sterile precautions, under general anesthesia and with angiographic and TEE guidance. Two TAVI systems have seen wide clinical application: the balloon-expandable Edwards Sapien valve (Edwards Lifesciences, Irvine, California), and the self-expandable CoreValve ReValving system (CoreValve, Irvine, California) (Figure 11).
When performing TAVI using the Edwards Sapien System, arterial femoral access is obtained by a femoral cutdown technique performed by one of the surgical members of the TAVI multidisciplinary team. Retrograde transarterial or antegrade transapical approaches are currently used to access the aortic valve. Balloon aortic valvuloplasty is performed before valve insertion to facilitate passage of the prosthesis through the stenotic native valve. With the balloonexpandable valve, ventricular burst pacing is used to decrease transvalvular flow and avoid expulsion of the system toward the aorta upon deployment. A percutaneous 6 French sheath is placed in the other femoral artery and one femoral vein. Heparin $50 \mathrm{U} / \mathrm{kg}$ IV is administered. The femoral artery access site is sequentially dilated to allow introduction of the large sheath to a position beyond the iliac arteries into the descending aorta. A pigtail catheter is then advanced through the femoral artery sheath and used to cross the stenotic aortic valve. Aortic root angiography is performed using the pigtail catheter placed from the other femoral artery to determine the optimal view for deployment. This optimal view is displayed during the procedure to facilitate subsequent positioning of the prosthesis. Aortic balloon valvuloplasty is performed under rapid ventricular pacing in a standard manner with a balloon diameter slightly smaller than the diameter of the planned prosthesis (Z-Med, Numed Inc, MAXY balloon valvuloplasty catheter, Cordis Incorporated, Johnson and Johnson, New Jersey). The retroflex steerable deflection catheter is used to actively direct the prosthesis through the tortuous aorta. The left anterior oblique view is the more helpful view to avoid foreshortening of the aortic arch. The prosthesis is then advanced into the left ventricle, carefully placed at the aortic annulus and deployed under rapid ventricular pacing and under angiographic and echocardiographic guidance. Optimal positioning of the prosthetic valve is critical if embolization, paravalvular insufficiency, and coronary obstruction are to be avoided; however, the precise methods and location of positioning remain to be established. Aortography and transesophageal echocardiographic assessment are helpful and are the most common imaging techniques used.

Appropriate position of the prosthesis as well as presence of any paravalvular leak is confirmed by TEE and angiography. Post valve implantation gradient and valve area are measured immediately after deployment of the prosthesis. The femoral arteriotomy is surgically closed and the patient is transferred intubated to the surgical intensive cardiac unit. Immediate hemodynamic and echocardiographic results are excellent providing abolition of the aortic gradient, a consistent post TAVI AVA $>1.6 \mathrm{~cm} 2$ and minimal post-procedure paravalvular leak. In hospital and long-term results are outstanding. ${ }^{27,28}$ 


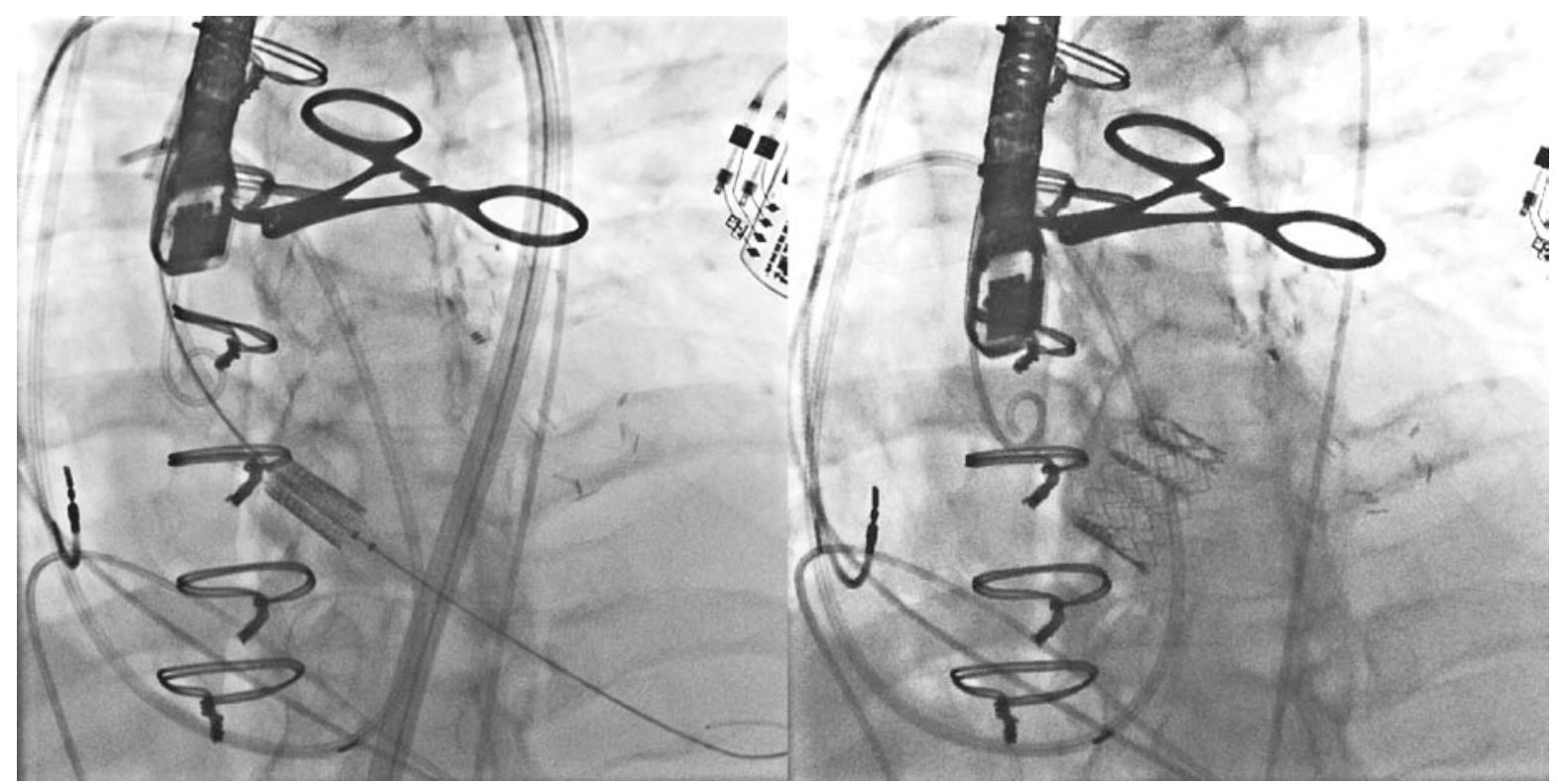

Figure 12. A transfemoral approach to TAVI using the Edwards Sapien Valve.

\section{TAVI results}

Leon et al reported in The New England Journal of Medicine that, for patients with severe aortic stenosis who are not candidates for surgery, Transcatheter Aortic-Valve Implantation (TAVI) using the Edwards SAPIEN valve significantly reduced mortality compared to standard medical treatment including PAV (results from Cohort B of the Partners I trial).

At one year, the rate of death from any cause was 30\% with TAVI vs. $50.7 \%$ with standard treatment. However, this method had a higher incidence of strokes and major vascular complications compared to standard treatment. TAVI is most common performed using the transfemoral approach (Figure 12). The safety of this technique depends on careful evaluation of the ilio-femoral and aorto-iliac vessels. Determination of vessels sizing, assessment of vessels tortuosity and concentric calcification are essential in the identification of ideal candidates for this approach. The implantation procedure involves accessing a femoral artery, performing retrograde aortic balloon valvuloplasty, then advancing the device across the native valve and deploy the aortic prosthesis during rapid right ventricular pacing under fluoroscopic and TEE guidance. Twoyear outcomes in the PARTNER B trial, ${ }^{29}$ showed that survival curves are continuing to separate and the number needed to treat to save one life dropped from five at one year to four patients at two. The FDA approved the Sapien valve for the US market, based on PARTNER B results. Two-year follow up data continue to support the role of TAVI as the standard of care for symptomatic patients with aortic stenosis who are not surgical candidates.

The Partners Trial Cohort A was comprised of $699 \mathrm{pa}-$ tients with severe, symptomatic aortic stenosis deemed at high risk for traditional open-heart surgery. ${ }^{10} \mathrm{~Pa}-$ tients were evenly randomised to receive either the Ed-
Transapical Approach to TAVI

\section{CTScan}

- Right common iliac artery $5 \mathrm{~mm}$

- Right external iliac artery $5.5 \mathrm{~mm}$

- Right common femoral artery $6 \mathrm{~mm}$

- Left common iliac artery $4 \mathrm{~mm}$

- Left external iliac artery $5 \mathrm{~mm}$

- Left common femoral artery $4.6 \mathrm{~mm}$

- Minimal descending aortic diameter $14 \mathrm{~mm}$

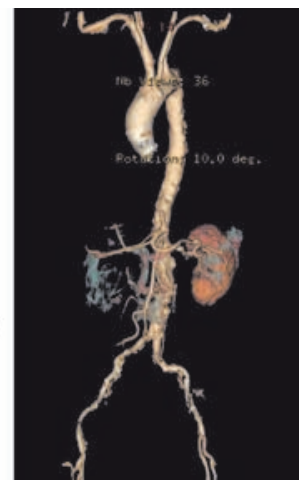

Figure 13. CT angio of a patient with severe aortic stenosis showing small size iliac-femoral vessels non compatible for transfemoral approach. He received a transapical Edawrds Sapien Valve.

wards SAPIEN valve with transfemoral (Figure 12) or transapical delivery (Figure 13 and 14) or traditional open-heart surgery. The study achieved its primary endpoint at one year, concluding that survival of patients treated with the Edwards SAPIEN transcatheter aortic valve was equivalent to those treated with surgical aortic valve replacement. In this cohort, the study found that TAVI was non-inferior to surgical aortic valve replacement (AVR) for all-cause mortality at one year, $24.2 \%$ versus $26.8 \%$, respectively. At one year, the rate of death from any cause was $30 \%$ with TAVI vs. $50.7 \%$ with standard treatment. However, TAVI patients had a higher incidence of strokes and major vascular complications compared to standard treatment. The rate of major strokes was $3.8 \%$ in the TAVI arm versus $2.1 \%$ in the surgery arm at 30 days and $5.1 \%$ versus $2.4 \%$ at one year, a difference that was not statistically significant $(\mathrm{p}=0.20$ at 30 days and 0.07 at one year). However, when strokes and transient ischemic attacks were considered together there was a statistically significant benefit favoring surgery at both 30 


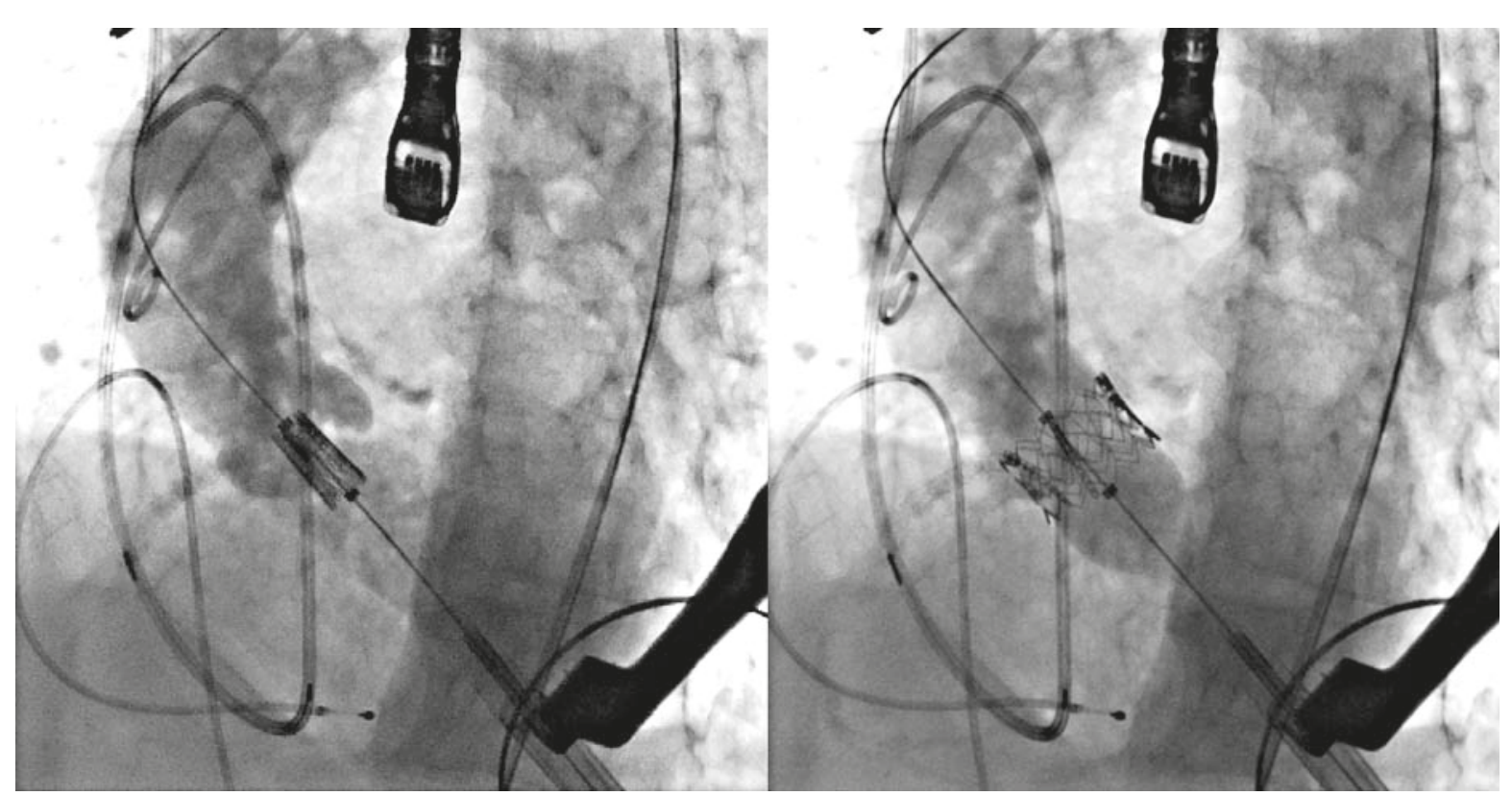

Figure 14. Successful transapical deployment of an Edwards Sapien valve in the patient described in Figure 13.

days and one year $(\mathrm{p}=0.04)$. Quality of life $(\mathrm{QoL})$ data analysis showed that high-risk, surgery-eligible patients treated via a transfemoral route in PARTNER A cohort had a substantial QoL benefits compared with surgery in the early weeks postprocedure. This was not the case for patients treated via a transapical route. In this later group of patients, there was no benefit of transcatheter aortic-valve replacement over surgical aortic-valve replacement at any time point, and in fact, QoL tended to be better with surgical replacement both at one and six months. ${ }^{29}$ Two years follow up data from the Partners I trial were recently reported by Dr. Susheel K. Kodali. ${ }^{30} \mathrm{He}$ reported that outcomes between TAVI and surgery were comparable at 2 years of follow up (Figure 15). Nevertheless, further follow up of this data is required because the main remaining question is what is the duration or longevity of the percutaneous valve. The more important news to address duration or longevity of TAVI will probably come from 4 or 5 years follow-up studies. The point that there is more aortic insufficiency with TAVI is valid. The fact that risk for stroke was not significantly different at 2 years is still not completely reassuring because it looks like more strokes occurred with TAVI than with surgical AVR [8 vs. 12 strokes].

A second prospective, randomized, multicenter trial, the PARTNER II trial, is currently ongoing and was designed to investigate the procedural clinical performance and outcomes after TAVI with the next-generation Edwards Sapien XT THV, as well as the new 18-F NovaFlex system (Edwards Lifesciences). The newer Sapien XT valve has several key differences from the previous-generation device, including a cobalt chromium frame and modified leaflet design that may improve durability. The PARTNER II cohort B includes patients with severe aortic stenosis deemed to be non- operable. In this trial cohort the "old device" versus "new device" non-inferiority trial was designed. The primary endpoint is a composite of death, stroke, and repeat hospitalization at 1 year. In addition, a cohort A of the PARTNER II trial will randomizes patients between TAVI with the Sapien XT valve and surgical AVR in moderate- to high-risk patients. This trial will enroll patients with a lower surgical risk score than the PARTNER I trial.

In December 2010, Medtronic commenced its U.S. pivotal trial designed to evaluate the safety and efficacy of the CoreValve system. The study will seek to enroll more than 1,300 patients at 40 clinical sites. The trial includes two studies in different patient populations: one study of patients diagnosed as high risk for aortic valve surgery and a second study of patients diagnosed as extreme risk. Patients deemed at extreme risk will not be randomized to optimal medical management; rather, they will be evaluated against a performance goal derived from contemporary studies. $\mathrm{Pa}$ tients in the high-risk group will be randomized oneto-one to either TAVI with CoreValve or to surgical aortic valve replacement. The primary endpoint will be all-cause death or major stroke within 12 months.

\section{TAVI Complications}

TAVI has become a reality in the management of patients with severe aortic stenosis and high or prohibitive risk for standard surgical management. Risks associated with TAVI differ from those related to surgical valve replacement and include vascular injury; stroke; cardiac injury such as heart block, coronary obstruction, and cardiac perforation; paravalvular leak; and valve misplacement. Awareness of how complications occur might help in their avoidance, recognition, and management. Ultimately, improved understand- 
A Death from any cause, intention-to-treat population

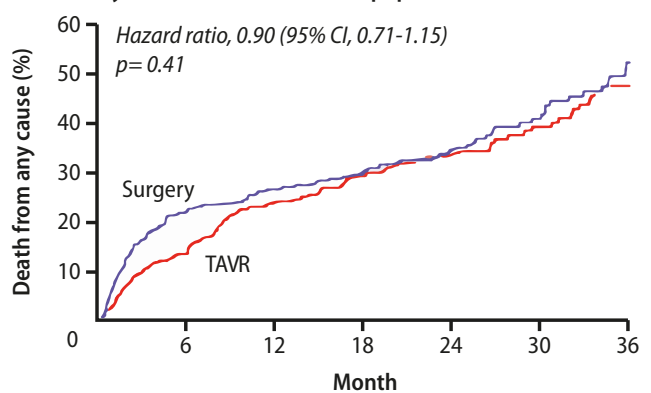

No. at risk

$\begin{array}{llllllll}\text { TAVR } & 348 & 298 & 260 & 234 & 172 & 70 & 31\end{array}$

$\begin{array}{llllllll}\text { TAVR } & 351 & 252 & 236 & 217 & 165 & 65 & 32\end{array}$

\section{Stroke, intention-to-treat population}

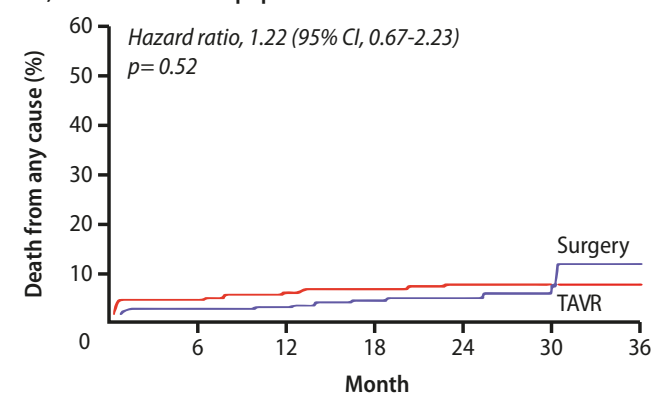

No. at risk

$\begin{array}{llllllll}\text { TAVR } & 348 & 287 & 249 & 224 & 162 & 65 & 28\end{array}$

B Death from any cause, as-treated population

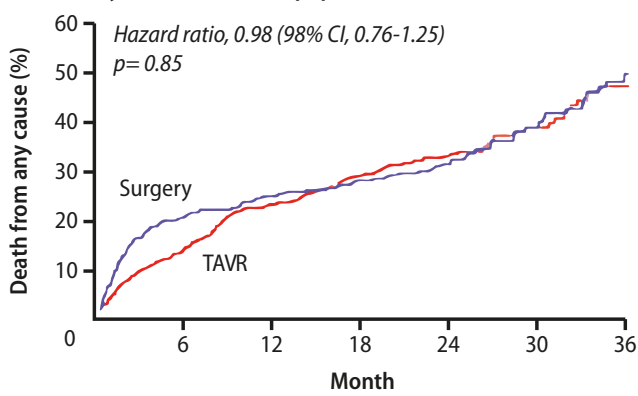

No. at risk

$\begin{array}{llllllll}\text { TAVR } & 344 & 291 & 259 & 232 & 155 & 70 & 29\end{array}$

$\begin{array}{llllllll}\text { TAVR } & 313 & 243 & 229 & 211 & 143 & 63 & 28\end{array}$

D Death from any cause or stroke, intention-to-treat population

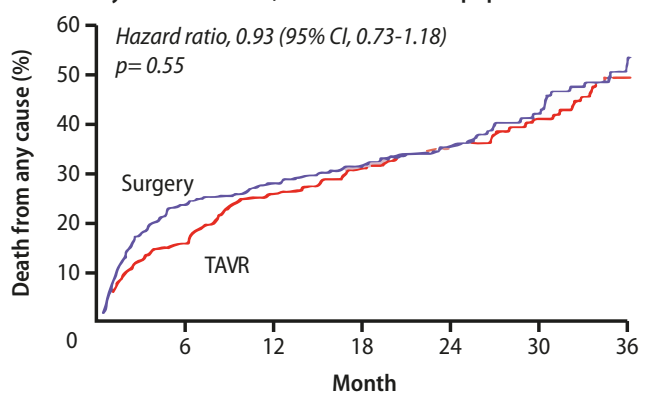

No. at risk

$\begin{array}{llllllll}\text { TAVR } & 348 & 291 & 254 & 230 & 168 & 68 & 29\end{array}$

$\begin{array}{llllllll}\text { TAVR } & 351 & 247 & 232 & 213 & 162 & 63 & 31\end{array}$

Figura 15. Time-to-event curves for the primary and other selected end points. Events were calculated with the use of Kaplan-Meier methods and compared with the use of a log-rank test. TAVR: transcatheter aortic-valve replacement. Use by permission New England Journal of Medicine: N Engl J Med. 2012 May 3;366(18):1686-95.

ing of the potential complications associated with TAVI might help improve outcomes and allow wider application of this therapy. ${ }^{30}$ The relatively large diameter of the delivery catheter has been a major limitation of transarterial TAVI. Early systems used 22- to $25-\mathrm{F}$ sheaths (outer diameter 9 to $10 \mathrm{~mm}$ ), and in the absence of adequate screening the incidence of arterial dissection and perforation was relatively high. Newer low-profile systems (e.g., CoreValve and Edwards NovaFlex) are compatible with smaller 18 -F sheaths (outer diameter approximately $7 \mathrm{~mm}$ ). It is reasonable to assume that the risk of vascular complications is reduced with the use of these lower-profile delivery systems. With technological advances, delivery catheter and sheath size will likely decrease further, which should be associated with further reductions in the risk of vascular injury and less stringent criteria for a transarterial approach. Angiography and multislice computed tomography is the main imaging modalities used to assess the presence and severity of iliac-femoral disease and determine the feasibility of an arterial approach. Minimal lumen diameter as well as the amount and distribution of atheroma, tortuosity, and calcification will determine the risk for vascular injury related to sheath insertion. Dissection or perforation of the iliac-femoral arteries might occur in the presence of ex- cessively traumatic sheath insertion. Dissection of the ascending or descending aorta can similarly occur due to catheter trauma or as an unpredictable complication of aortic valvuloplasty. Non-occlusive retrograde arterial dissection will commonly heal once antegrade flow is restored; therefore limited dissections are often best managed conservatively. More extensive arterial dissection can be managed with endovascular stenting although on occasion surgical repair might be necessary. For patients with unsuitable femoral access, alternatives include the LV apical, subclavian, open iliac or ascending aorta approaches, or reconstruction of iliac-femoral axis with stents or grafts. Although a large experience exists with the apical procedure, experience with the other approaches is limited. Strokes represent a serious and concerning complication of TAVI. The most frequent etiology of procedural stroke is likely to be atheroembolism from the ascending aorta or the aortic arch. Other potential causes include calcific embolism from the aortic valve, thromboembolism from catheters, air embolism from LV cannulation, prolonged hypotension, and dissection of arch vessels. Balloon dilation of the native valve is typically performed before valve implantation to ease insertion of the crimped prosthesis. Repeated or overly aggressive valvuloplasty might be associated with an increased 
risk of embolization of calcific material from the aortic valve and should be avoided. The incidence of stroke varies in the published reports as the consequence of the learning curve, the evolution in technique, and equipment but also the completeness of neurologic assessment. With current devices and experience, stroke rate ranges from $0 \%$ to $10 \%$. Some authors have suggested that stroke risk might be lower with transapical access due to less manipulation in the aortic arch, but this has not been a universal finding. In the future, increased procedural experience, less traumatic valve delivery systems, screening for thick aortic atheroma, and possibly embolic protection devices currently under development might lower the risk of stroke. Procedural anticoagulation to reach a target activated clotting time over $250 \mathrm{~s}$ is generally suggested. The longerterm thromboembolic risk associated with transcatheter valves is currently unknown. Empiric dual oral antiplatelet therapy is generally recommended for 3 to 6 months, followed by long-term daily low-dose aspirin. An ideal transcatheter aortic prosthesis would restrain the native leaflets and relieve stenosis without unnecessary contact with the surrounding structures. A valve extending excessively into the ventricle or the aorta might be associated with adverse events such as mitral insufficiency, arrhythmias, coronary artery ostium occlusion, or aortic injury. Prosthesis embolization immediately after deployment is generally the result of a gross error in positioning or ejection of the device by an effective ventricular contraction during deployment. Coronary obstruction might occur if an obstructive portion of the valve frame or the sealing cuff is placed directly over a coronary ostium; however, this is exceedingly rare. Minor paravalvular regurgitation is rare with current transcatheter valves, but the incidence of moderate or severe paravalvular leaks was greatly reduced by the routine insertion of prostheses larger than the measured annulus diameter. Initial reports suggested significant paravalvular leak in many patients after implantation of the first-generation balloon-expandable TAVI, but more recent publications report infrequent cases of moderate or severe paravalvular regurgitation with both systems. Mild and even moderate degrees of paravalvular regurgitation seem to be well-tolerated, and clinically significant hemolysis has not been observed to date. However, moderately severe or severe paravalvular, albeit infrequent, is likely to be hemodynamically significant. The initial sign is typically an unexpectedly low aortic diastolic pressure. Rising ventricular filling pressure might lead to myocardial ischemia, ventricular dysfunction, and ultimately shock. The diagnosis is confirmed with aortography or, more reliably, echocardiography. Most likely causes are incorrect positioning, undersizing, or underexpansion. Balloon re-expansion might be helpful in cases of incomplete expansion, whereas a second overlapping prosthesis might be the most effective so- lution for leaks caused by malposition. Exclusion of patients with an annulus larger than the largest available prosthesis is prudent to avoid significant paravalvular regurgitation. Finally, atrioventricular block is a known complication of surgical aortic valve replacement with reported incidence up to $8.2 \%$. Not surprisingly, block can also occur with TAVI, presumably as a consequence of the pressure applied on the conducting tissues located subendocardially in the LV outflow tract and interventricular septum. In initial reports of TAVI-induced heart block with the 2 currently used systems, permanent pacemaker implantation rate was $7 \%$ for the Edward Sapien valve and $18 \%$ for the CoreValve system. Early experience suggests that prostheses extending farther in the ventricle are associated with a higher incidence of conduction abnormalities, most likely new-onset left bundle branch block. Potential risk factors also include aggressive oversizing and the presence of pre-existing infranodal conduction anomalies such as right bundle branch block or second-degree heart block. Heart block typically manifests immediately after valvuloplasty or valve implantation. Consequently, placement of a temporary pacemaker is desirable during the procedure. In rare cases heart block has appeared days after the procedure; and postprocedural monitoring for $48 \mathrm{~h}$ has been suggested.

\section{PATIENT SELECTION - ROLE OF A MULTI- DISCIPLINARY TEAM APPROACH TO TAVI}

In the PARTNER trial, the criteria used to define severe degenerative aortic valve stenosis was an echocardiographic crirteria which included an aortic valve area of $<0.8 \mathrm{~cm}^{2}$ (or aortic valve area index $<0.5 \mathrm{~cm}^{2}$ ) $\mathrm{m}^{2}$ ), a mean systolic aortic gradient of $>40 \mathrm{~mm} \mathrm{Hg}$, or a peak aortic jet velocity of $>4 \mathrm{~m} / \mathrm{s}$. All patients were symptomatics from aortic stenosis, they had a New York Heart Association functional class $\geq 2$. Some of the exclusion criteria included recent acute myocardial infarction ( $\leq 1$ month), recent stroke or transient ischemic attack (within 6 months), congenital unicuspid or bicuspid aortic valves, a preexisting prosthetic heart valve in any position, severe ventricular dysfunction (left ventricular ejection fraction $<20 \%$ ), renal insufficiency (creatinine $>3 \mathrm{mg} / \mathrm{dL}$ ), and a life expectancy $<$ 12 months. Surgical inoperability was judged by a cardiac interventionist and two separate surgical investigators and was based on a 30-day probability of death or serious, irreversible condition $>50 \%$ after surgical valve replacement. In addition, high-risk surgical candidates, were characterized by a Society of Thoracic Surgeons risk score $>10 \%$ and the presence of comorbidities resulting in a $\geq 15 \%$ predicted 30 -day mortality, as assessed by a cardiac surgeon.

The immediate and intermediate long-term outcomes of TAVI have provided happiness and enthusiasm to interventional cardiologists who felt that they 
have conquered the percutaneous treatment of calcific aortic stenosis. However, TAVI is vastly a multidisciplinary team approach, and a collaborative exercise for the heart valve team is necessary for successful program outcomes. ${ }^{31,32}$ Optimal patient selection is critical to a successful TAVI procedure. This multidisciplinary team is essential in the screening, intra procedural, post procedural and follow up of these patients, and plays a big role given his multiple expertises. Patients should be screened into a TAVI program by a member of the multidisciplinary team, and not by any individual specialties. Selection of candidates for TAVI should involve multidisciplinary consultation between interventional cardiologists, surgeons, echocardiographers and other imaging specialists, anesthesiologists, pulmonologist, and other specialties if necessary. The use of a team approach has been shown to improve outcomes in these types of complex procedures. Transcatheter AVR is performed with either local or spinal anesthesia; with sedation or with general anesthesia in a cardiac catheterization laboratory, or in an operating room equipped with fluoroscopy and transesophageal echocardiography. TAVI is performed either through transfemoral or transapical approach. The concept of a hybrid room was developed for this technique and requires a large dimensions room equipped with High Resolution Fluoroscopy and Cineangiography, with Dyna CT (Siemens USA, Washington D.C, USA) and TEE Capability. It requires Double ventilation circulation and a readily available Heart Lung Machine, IABP and Pacemaker. The screening tests usually necessary in these patients evaluation include clinical evaluation, EKG, TTE and TEE, Chest, abdominal and pelvic CT angiography, Cardiac catheterization with coronary arteriography, PFTs, non-invasive carotid studies. Surgical risk of the patients is accomplished by the use of special scoring methods for risk stratification. They include the EuroSCORE, the STS Score, and the Frailty Score. When test are completed the results of the evaluation are openly discussed with the multidisciplinary group to see what is the best way forward for each individual patient.

Assessment of the anatomy of the aortic annulus is an important component of case selection. Both manufacturers currently have only two sizes of bioprosthesis in widespread use to treat a wide range of annuli. They have thresholds for sizing of their respective prostheses for the annular dimensions of a particular patient dictated by estimated need for oversizing. It is clear that measured dimensions by various imaging modalities employed for this purpose vary significantly. While transthoracic echocardiography acts as a useful screening tool in this regard, transesophageal echocardiography, sometimes as an immediate pre-TAVI confirmatory evaluation, is regarded as the current standard of care. Computerized tomography provides additional information regarding the noncircular nature of the aortic annulus, which is poorly appreciated by echocardiographic modalities. Each manufacturer has set clear boundaries for each of their respective bioprosthesis sizes. The Edwards Sapien device requires an annulus of $18-21 \mathrm{~mm}$ for its smaller $23 \mathrm{~mm}$ bioprosthesis and $22-25 \mathrm{~mm}$ for its larger $26 \mathrm{~mm}$ bioprosthesis, with $21-22 \mathrm{~mm}$ remaining a 'gray zone', at the operator's discretion. A larger $29 \mathrm{~mm}$ Edwards Sapien device now has CE mark for the transapical route. The Medtronic Core Valve device requires an annulus of 20-23 $\mathrm{mm}$ for its smaller $26 \mathrm{~mm}$ bioprosthesis and 24$27 \mathrm{~mm}$ for its larger $29 \mathrm{~mm}$ bioprosthesis. Although $23-24 \mathrm{~mm}$ is an unspecified gray zone, the larger bioprosthesis is generally prescribed for these dimensions. Recently, there has been a further iteration of the Edwards Sapien device, the XT, with a corresponding reduction in profile $18 \mathrm{Fr}$ (minimum femoral dimension $6 \mathrm{~mm}$ ) and $19 \mathrm{Fr}$ (minimum femoral dimension $6.5 \mathrm{~mm}$ ) respectively. However, these sheath sizes are based on internal dimensions of the access sheaths, which have larger external dimensions. Indeed, femoral access risk ratio, defined as sheath size $(\mathrm{Fr}) / \mathrm{min}$ imal FA diameter $(\mathrm{mm})$, with a threshold of 2.6 , has been identified as an independent predictor of major vascular complications. ${ }^{33}$ This study suggests that to avoid major vascular complication, minimal femoral dimensions of $7.0 \mathrm{~mm}$ for $18 \mathrm{Fr}, 7.3 \mathrm{~mm}$ for $19 \mathrm{Fr}$, $8.5 \mathrm{~mm}$ for $22 \mathrm{Fr}$ and $9.2 \mathrm{~mm}$ for $24 \mathrm{Fr}$ should be employed. The same study has also shown that excessive calcification at the site of femoral access is an independent risk factor for major vascular complication..$^{33}$

The future of percutaneous aortic valve replacement depends on the development of smaller diameter collapsible, repositionable, and compressible valve prostheses, anti-calcification treatment, and adjunctive techniques to decrease the incidence of cerebrovascular embolic events. TAVI is definitely a breaking through technique that has revolutionized the treatment of aortic stenosis at the entrance of this century. Although today these techniques are targeted at high-risk patients for AVR, they may be extended to the lower risk groups in the future, if the initial promise holds true after careful evaluation. The road is long and demanding, but the interventionalist dream for percutaneous aortic valve replacement has become a reality. Further development and improvement of current available TAVI devices are expected to increase success, decrease complications and broaden TAVI indication to larger number of patients. The next generation of devices may help reduce the frequency of procedure-related complications. In these older patients with vascular disease, it is difficult to insert the larger device used in the PARTNER trial. The next-generation devices, such as the Sapien XT [Edwards] that is 40 percent smaller and more durable or the EU-approved CoreValve [Medtronic], will obviate the vas- 
cular complications and reduce the bleeding complications. The Sapien valve system initially used has evolved and current platforms are now $4^{\text {th }}$ generation, which is much smaller diameter $(18 \mathrm{Fr})$ and so, should decrease vascular complication and stroke rates. These complications will be further reduced as operator experience increases and potentially with the routine use of embolic protection devices. If stroke rates are reduced then certainly TAVI will march even further forward and may well be tested in lower risk populations with aortic stenosis in whom surgery is indicated. Such optimism should be welcomed by both patients and interventionists alike, but only after rigorous evaluation of efficacy and longer-term durability of TAVI have been convincingly demonstrated.

\section{RESUMEN}

\section{Intervenciones percutáneas aórticas en pacien- tes con estenosis valvular aórtica severa}

El tratamiento de elección de la estenosis aórtica severa sintomática sigue siendo el reemplazo de la válvula aórtica (AVR).

La Valvuloplastía aórtica percutánea (PVA) está asociado con mejoría de los síntomas y los parámetros hemodinámicos pero sus principales limitaciones son las complicaciones mayores así como la alta tasa de restenosis al año.

Se presentan 310 pacientes con estenosis aórtica severa sintomáticos no candidatos quirúrgicos consecutivos que recibieron 394 PVA entre los años 1986 y 1993 en el Massachusetts General Hospital. A un grupo de estos pacientes se les realizo en el seguimiento un reemplazo de válvula aórtica (AVR). Cuando se comparo estos dos grupos de pacientes, aquellos que recibieron PVA como puente a un AVR presentaron mayor sobrevida al seguimiento alejado que los pacientes que solo recibieron PVA.

\section{REFERENCES}

1. Straumann E, Kiowski W, Langer I, et al. Aortic valve replacement in eldelry patients with aortic stenosis. British Heart Journal. 1994; 71: 449-53

2. Pupello DF, Bessone LN, Hiro SP, et al. Aortic valve replacement: procedure of choice in elderly patients with aortic stenosis. Journal of Cardiac Surgery. 1994: 9 (2 Suppl (: 148-153

3. RuygrotPN,Barratt-BoyesBG,AgnewTM, CoverdaleHA, Kerr AR, WhitlockRM. Aorticvalvereplacementintheelderly.Journal of Heart ValveDisease. 1993;2:550-557.

4. Aranki SF, Rizzo RJ, Couper GS, et al. Aortic valve replacement in the elderly. Effect of gender and coronary artery disease on operative mortality. Circulation 1993; 88: // 17-23

5. Fighali AU, Sayid F, Avendano A, et al. Early and late mortality of patients undergoing aortic valve replacement after previous coronary artery bypass graft surgery. Circulation 1995;92(9):II-163-1I-168.

6. Fremes SE, Goldman BS, Ivanov J, Weisel RD, David TE, Salerno T. Valvular surgery in the elderly. Circulation 1989: 80(3 Pt 1): I-77-90.

7. Smith N, McAnulty JH, Rahimtoola SH. Severe aortic stenosis with impared left ventricular function and clinical heart failure: results of aortic valve replacement. Circulation 1978;58: 255-264.
El subgrupo de pacientes con estenosis aórtica severa y shock cardiogénico presentan mejoría significativa de los parámetros clínicos y hemodinámicos.

Desde que Alan Cribier en el 2002 implantara la primera válvula aórtica por vía percutánea (TAVI) en un paciente inoperable este método se ha expandido en forma exponencial. Usándose actualmente dos tipos de dispositivos, la válvula balón expandible (Edwards Lifesciens, Irvine, California) y la válvula autoexpandible (Core Valve, Irvine, California). El ensayo Partner Cohorte $\mathrm{B}$ fue el primer ensayo randomizado que comparó pacientes con estenosis aórtica severa sintomáticos inoperables a TAVI versus terapia estándar, donde se observó que la mortalidad con el TAVI fue significativamente menor que con la terapia estándar. Esta diferencia se mantuvo al cabo de dos años. En base a este ensayo en el año 2011 la FDA aprobó el uso de este dispositivo para pacientes inoperables. El ensayo Partner Cohorte A comparó en forma randomizada pacientes con estenosis aórtica severa sintomática de alto riesgo quirúrgico a TAVI versus AVR, donde se observó que el TAVI fue no inferior al AVR al año de seguimiento. Sin embargo la tasa de stroke fue mayor el grupo percutáneo. Dentro de las limitaciones que presentan el TAVI se encuentra el stroke, la insuficiencia aórtica perivalvular, las complicaciones en los accesos y la necesidad de nuevo marcapasos.

El sueño del implante de válvula aórtica percutánea es una realidad. La selección del paciente, la utilización de diferentes imágenes para evaluar la válvula, así como el rol del equipo multidiciplinario es vital para llevar a cabo un implante eficaz. El continuo desarrollo y perfeccionamiento de estos dispositivos serán la clave para que se incremente el éxito, disminuyan las complicaciones y se extiendan las indicaciones a diferentes grupos.

Palabras clave: estenosis aórtica, implante válvula aórtica percutáneo, alto riesgo

8. Carabello BA, Green LH, Grossman W, Cohn LH, Koster JK, Collins JJ Jr. Hemodynamic determinants of prognosis of aortic valve replacement in critical aortic stenosis and advanced congestive heart failure. Circulation 1980;62:42-48.

9. Elayda MA, Hall RJ, Reul RM, et al. Aortic valve replacement in patients 80 years and older. Operative risks and long-term results. Circulation 1993; 88: $1111-16$

10. Hutter A Jr, De Sanctis R, Nathan M, et al. Aortic valve surgery as an emergent procedure. Circulation 1970: 51:623-7

11. Kirklin JW. Aortic valve disease. In: Kirklin JW, Barrat-Boyes B, editors. Cardiac Surgery: Morphology, Diagnostic Criteria, Natural History, Techniques and Indications. New York: Churchill Livingstone, 1993:528

12. Levinson JR, Akins CW, Buckley MJ, et al. Octogenarians with aortic stenosis. Outcome after aortic valve replacement. Circulation 1989; 80: (3 Pt 1) $149-156$

13. Cribier A, Savin T, SaoudiN, RochaP, BerlandJ, Letac B. Percutaneoustransluminal valvuloplasty of acquired aortic stenosis in elderly patients: an alternative to valve replacement? Lancet 1986:1 (8472): 63-67. 
14. Block PC, Palacios IF. Aortic and mitral balloon valvuloplasty: the Unites States experience. In: Topol EJ, editor. Textbook of Interventional Cardiology. 2ndedition. WBSaunders Company, Philadelphia, PA. 1994:1189-205.

15. BlockPC, Palacios IF.Comparison of hemodynamicresults of anterogradeversus retrograde percutaneous balloon valvuloplasty. Am J Cardiol 1987;60:659-662.

16. McKay RG, for the Mansfield Scientific Aortic Valvuloplasty Registry: BaIloon aortic valvuloplasty in 285 patients: initial results and complications. Circulation 1988; 78:11-594.

17. Block PC, Palacios IF. Clinical and hemodynamic follow-up after percutaneous aortic valvuloplasty in the elderly. Am J Cardiol 1988 (62):760-763.

18. Palacios IF. Percutaneous aortic balloon valvuloplasty. In: RobicseckF, editor. Cardiac Surgery: State of the Art Reviews. Hanley \& Belfus, INC. Philadelphia, PA. 1991; Vol 5, No. 2: 267-27.

19. Moreno PR, Jang I-K, Newell JB, Block PC, Palacios IF. Percutaneous aortic balloon valvuloplasty in the elderly: The Massachusetts General Hospital experience. Circulation 1993; 88: I-340.

20. Otto CM, Mickel MC, Kennedy JW, et al. Three year outcome after balloon aortic valvuloplasty. Insights into prognosis of valvular aortic stenosis. Circulation 1994; 89:642-650.

21. Moreno PR, Jang IK, Newell JB, Block PC, Palacios IF. The role of percutaneous aortic valvuloplasty in patients with cardiogenic shock due to severe aortic stenosis. J Am Coll Cardiol 1994; 23: 1071-1075.

22. Rahimtoola SH. Catheter balloon valvuloplasty for severe calcific aortic stenosis: a limited role. J Am Coll Cardiol. 1994;23:1076-1078.

23. Gorlin R, Gorlin G. Hydraulic formula for calculation of area of stenotic mitral valve, other cardiac values and central circulatory shunts. Am Heart J. 1951;41:1.

24. Ford L, Felman T, Chiu C, et al. Hemodynamic resistance as a measurement of functional impairment in aortic valve stenosis. Circulation Research 1990;66:1-7
25. Bonhoeffer P, Boudjemline Y, Saliba Z, et al. Percutaneous replacement of pulmonary valve in a right-ventricle to pulmonary-artery prosthetic conduit with valve dysfunction. Lancet. 2000; 356: 1403-1405

26. Cribier A, Eltchaninoff $H$, Bash A, et al. Percutaneous transcatheter implantation of an aortic valve prosthesis for calcific aortic stenosis: first human case description. Circulation Dec 2002;106:3006-3008.

27. Inoue K, Owaki T, Nakamura T, Kitamura F, Miyamoto N. Clinical application of transvenous mitral commissurotomy by a new balloon catheter. J Thorac Cardiovasc Surg 87: 394-402, 1984

28. Palacios IF. Percutaneous valve replacement and repair: fiction or reality? J Am Coll Cardiol 2004; 44: 1652-1661.

29. Reynolds MR, Magnuson EA, Wang K, et al. Cost-effectiveness of transcatheter aortic valve replacement compared with standard care among inoperable patients with severe aortic stenosis: results from the Placement of Aortic Transcatheter Valves (PARTNER) Trial (Cohort B). Circulation. 2012;125:1102-1109.

30. Kodali SK, Williams MR, Smith CR, et al, for the PARTNER Trial Investigators. Two-Year Outcomes after Transcatheter or Surgical Aortic-Valve Replacement. NEJM 2012: 10; 1056-

31. Neily J, et al., Association between implementation of a medical team training program and surgical mortality. JAMA: the Journal of the American Medical Association, 2010, 304: 1693.

32. Palacios IF. Percutaneous Aortic Valve Replacement. The Multidisciplinary Approach. The Key to Success. Revista Española de Cardiología, 2012 (in press).

33. Hayashida K, Lefèvre T, Chevalier B, et al. Transfemoral Aortic Valve Implantation. New Criteria to Predict Vascular Complications. J Am Coll Cardiol Intv, 2011; 4:851-858. 